\title{
VIRTUAL MUSEUMS AS DIGITAL STORYTELLERS FOR DISSEMINATION OF BUILT ENVIRONMENT: POSSIBLE NARRATIVES AND OUTLOOKS FOR APPEALING AND RICH ENCOUNTERS WITH THE PAST.
}

\author{
S. Caspani ${ }^{\text {a }}$, R. Brumana ${ }^{\text {a }}$, D. Oreni ${ }^{\text {a }}$, M. Previtali ${ }^{\text {a, * }}$ \\ ${ }^{a}$ Dept. of Architecture, Built Environment and Construction Engineering (ABC), Politecnico di Milano, 20133 Milan, Italy - \\ (sara.caspani, raffaella.brumana, daniela.oreni, mattia.previtali)@polimi.it
}

Digital Workflows for Heritage Conservation

KEY WORDS: Virtual Museum, Digital Storytelling, Built Environment, Cultural Awareness, New Technologies, Social Media

\begin{abstract}
:
Virtual Museums (VMs) have emerged from the ongoing crossbreeding process between museums and digital technologies as an additional "channel" for disseminating content and providing knowledge about cultural heritage. VMs is a concept still in definition, as this paper attempts to briefly retrace, the recognition of its potential has motivated our efforts for further developments.

Core questions that motivated the first phase of the research presented have been: can digital storytelling become the key feature of future VMs? May narratives approach support communication and understanding of cultural heritage providing enriching encounters with the past? May complex systems, such as the built environment and landscape (characterized by space-time relations among elements, that are often difficult to read or appreciate) find in digital storytelling a method that exploits their values as documents and palimpsests of human history? Can an increased awareness of the past contribute to support a sense of belonging and identity construction? Which kind of stories can be currently designed with the existing tools?

The paper, after an introductory overview, provides a tentative reply to these questions combining the main findings offered by a series of recent studies related to this scenario with some preliminary direct investigations and, eventually, it proposes some outlooks for future developments.
\end{abstract}

\section{INTRODUCTION}

This research, complementing the general field of cultural heritage enhancement specifically refers to the world of new forms of museums. Which, opened by the blooming of the world wide web and the increased availability of digitalized data goes under the name of Virtual Museums (VMs). VMs, have been on the stage as cultural actors since the nineties. After almost three decades, considering that the internet is a mature media and technologies that can well support new perspectives, it seems time to reflect on what role the internet can cover in the future of Cultural Heritage $(\mathrm{CH})$ and on which aspects, according to the most recent State of the Art (SoA) can be more relevant to work in. Capturing in parallel some pivotal changes occurring in Museums and what has been occurring in VMs up to today, even though in brief and without ambition of completeness, it has been the pathway chosen aiming to support the development of the latter.

\section{VIRTUAL MUSEUM TO COMMUNICATE CH SoA \& BEYOND}

What the Museum is and what mission it should have are two concepts that have evolved since the time of Palazzo Medici and the sixteenth-century practice of private collecting. A similar process is ongoing that has been characterizing by the young digital counterpart of the Institution mainly in strict relation to the extremely rapid evolution of the technological domain. Up to today only in few cases there have been a solid theoretical proposal about the role that VMs may cover, quite apart from technological contingencies of the moment. In fact, even if the theoretical ground of VMs is traced by many in the André Malraux's idea of a museum without wall, a full transposition of its hypothetical richness has struggled to emerge, at least at the present (Schweibenz, 1998 and Huhtamo, 2010). Probably, it is precisely in the absence of a general reflection upstream and in the speedy evolution of tools and media available that the heterogeneousness of the galaxy of what is called VMs finds nourishment and explanation. The need to frame and circumscribe the phenomena, to carry out a general analysis able to trace the state of the art and prefiguring the afterwards, has become pivotal indeed (Schweibenz, 2004). Under this light one of the most complete attempts was made within the European project v-must (Virtual Museum Transnational Network) that opens its legacy in proposing a work in progress definition. It is tentative and far from being complete, however it is noteworthy because, at first, it declares the principle of exclusion in order to check the lay of the land, clearly highlighting the challenge underpinning in framing what arrived nowadays. Secondarily, assuming the definition adopted by ICOM in 2007 as canvas, the choice would stress that the paramount goals in terms of meaning and mission of VMs are along the same track of those that characterize the brick and mortar ones. Furthermore, this latest aspect can be read as a thinly veiled suggestion to restart properly from the Museum to design the virtual one, as is done here.

In recent years, museums have been attempting to do more than preserving and conserving artworks and remains. The collections have always been at the centre of the museums, but their role have shifted from showing the power of the prince or being available to erudite scholars, as happened during

* Corresponding author 
Renaissance, towards being the "channel", the "excuse" to intertwine organic relations, stories, and links with and among people. Within the modern museums, although the collection presented to the public still remains a subjective selection, a sample from many that the curators can choose, the will to disclose relations and contexts, exploiting the objects to support people in richer and compelling "rendezvous" with the past, is the main driver. Prioritizing themes, ideas and relationships may be considered one of the strengths of the modern museum (Hooper-Greenhill, 2005). This trend opens up the opportunities to define new methods of interpretation that are especially suitable for presenting complex system such as the built environment (BE) and landscapes in a museum. In these cases, in fact, acknowledgment of their values is subtended to the actual capability to read, understand, communicate relations among elements, often no more visible, that occur in space and time.

Additionally, museums have been called to open up their doors to an increasingly wider audience. This has asked them to define alternative modalities of encounters that may be especially appealing for those categories who are not usually accustomed visitors, as, for instance, teenagers are, as well as to push for using cultural heritage as tool to foster a reflective behaviour and sense of belonging within societies.

Expectations, as seen above, are many. Howbeit, looking at museums as quintessentially a storyteller seems to be the cornerstone to deal with most of them progressively. Narrative is a powerful tool for museums because it follows in structure how people learn. Human beings make sense of the world and themselves through narrative and it is basically the instrument for making meaning. (Bruner, 1990). Storytelling is a method of interpretation, a way to inspire an internal dialogue and ensure a real connection with visitors as well as a strategy for realizing an environment where visitors are encouraged to create their own meaning (Bedford, 2001 and Wong, 2015). Storytelling in museums exploits the enormous potential of objects and even more of cultural systems that can find in storytelling a method by which interrelations and mutual effect among places, persons, material culture, traditions come out.

All of these features clearly suggest storytelling in museums as a possible way and, taking it to the extreme level, museums can be seen as storytellers in themselves (Johnsson, 2006). In spite that, storytelling is not once and for all. Linear, and non-linear, fragmented narratives are only some traditional models studied and developed by scholars such as William Labov and Vladimir Propp. The black spot, whatever is the model chosen, it is that storytelling is usually destined to be few user-adjustable as well as unique in space and time if it is led outside digital domain. It is likely to be the additional top-down reading key, curator centred, or, at least, it risks losing part of its potential in offering different points of view and in being able to actually engage new target groups. Those limitations are crucial for museums but not easily conquerable within their walls. Instead, VMs appear the optimal environment where these constraints can be deluded.

Up to today, VMs have been many things there is not a single model of VM, and it is not merely a matter of definition of course. Under the name of VM are virtual tours, digitalized collections, and dedicated webpages are common place. The link with the "mother" museum is often palpable not to say mutually exclusive but definitely in all the forms already tried out, a more democratic access to culture has been supported. Making accessible collections on the web or allowing users to navigate the space of the museums from their home has been an important step forwards, but we think they are not the ultimate destination or the maximum potential of VMs.
Important project such as Google Art \& Culture or Europeana (http://www.europeana.eu/) could do something more. They have offered access to different museums or collections from a single webpage, making users lives easier and enriching the experience in term of content available and content automatically suggested thanks to a well-structured internal system of semantic research. However, they still struggle to show what there is beyond the digitalized object in itself.

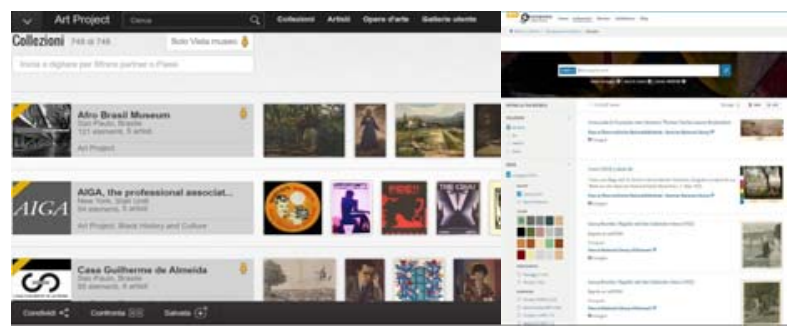

Figure 1. Google Art Project \& Europeana. Examples that exemplify the presentation of digital collection as catalogue.

\section{DIGITAL STORYTELLING FOR VM}

\subsection{Looking in prospective}

The main purpose to invest in VMs development lies in the fact of making accessible and comprehensible the tangled relations that in other ways are difficult to be appreciated and understood by the general public. Moreover, we believe that the scenario opened by the narrative approach may contribute to support a sense of belonging and identity construction that many professionals are confident cultural heritage should have, especially with regards to field sites which have controversial and tangled histories, of which Europe has many (1), (2), (3). We look first of all, at Europe because besides being directly the closest reference environment, it is an entity still in the process of being fully made into its own by society, where the discrepancy between the Institution and "popular feeling" is palpable.

Here, probably more than elsewhere, the memory, heritage and identity of a systemic approach is the main option to trace and image a future according to the view that "How we conceive the future has implications for how we conceive the present and the past - and vice versa." (Macdonald, 2013).

When national states were constituted, museums, in quality of legitimated repository of culture, supported national identities construction. Today, we are faced with a new, young and not completely mature Institution as Europe is, placed side by side to the pre-existing national level, adding further complexity to the issue. People have always possessed different cultural identities (Castell, 2000) (Bauman, 2003), so, the matter is not how to replace their national identity with the European one. The "Declaration of European Identity" (Copenhagen, 14 December 1973), even if quite abstractly, suggested that a multi-levelled diversity is the distinctive feature of European Identity. Museums, in this context, should provide a multi-

\footnotetext{
${ }^{1}$ See the Manifesto of the HORIZON 2020 project CulturalBase (Social Platform on Cultural Heritage an European Identities) http://culturalbase.eu/

2 For instance, the no-profit association CHwB (Cultural Heritage without borders) in its strategic plan 2013-16 declares "Cultural heritage is used as a tool for creating a better understanding of our shared and diverse pasts and as a building block in the effort to promote democratic development."

3 EUROPEAN COMMISSION, 2014, Towards an integrated approach to cultural heritage for Europe.
} 
perspective history, feeding different narrative thrusts, recognizing multiple memories, and use the capabilities of heritage to accommodate different kinds of identities. Virtual Museums allow to think about a new narrative able to operate along this trace in particular whether or not they are built up as copy of the traditional Institution.
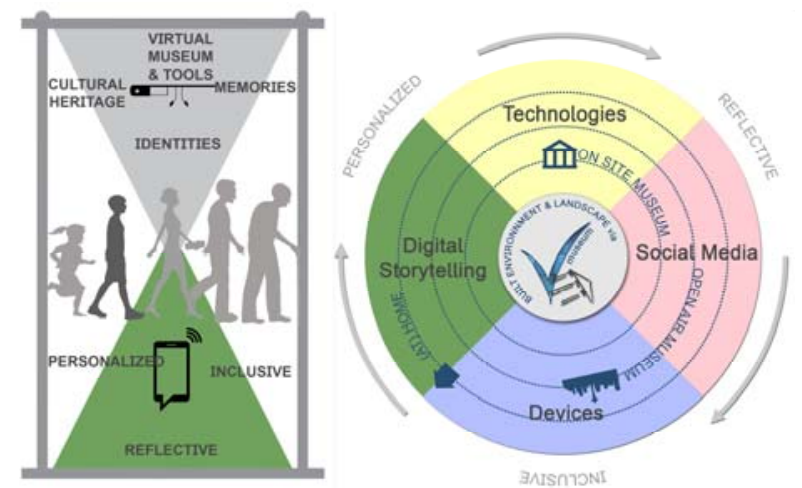

Figure 2. Concept framework of innovative model of VM for Built Environment \& Landscape

Digital narrative may be used to show how objects of material culture have different valences in different parts of Europe. It may be the glue to connect the various points of view about controversial historical events and much more. VMs and their narrative can raise cultural awareness of heritage and places. They can foster meaningful inter-cultural dialogue, engender respect for cultural differences, they may be the place where recognition of diversity, in all its aspects, embodies openmindedness, if not unity, dusting the slogan "Unity in diversity" from onerous expectations. Digital storytelling is loaded with many expectations and sometimes too many. We acknowledge that dealing with new forms of narrative for the provocateurs of memory, in our case virtual, (Poulot, 2015) calls museums, it is not a definitive reply and it is far to be our first objective but, at the same time, we are confident that proposing ways to recount the history, appropriate to our time and to our way of content consumption, may have a good impact.

\subsection{Models of digital storytelling for museums}

The specific definition of digital storytelling refers often to the media practices created and disseminated through the Berkeleybased Center for Digital Storytelling. At the beginning of nineties and over time, other definitions have been proposed in reference to specific approaches. However, in a general sense we assume that digital storytelling (DG) “...is a creative process combining the art of telling stories and technology with the aim to develop a personal story in digital format..." (Silvaggi \& Braga, 2013, 51). Interest in digital storytelling emerged at the beginning outside museum's walls. Online journalism, before any others, in consideration of the everincreasing number of content and proliferation of competition within a globalized reference market, has invested in developing strategies for appealing contents that are able to attract cyber users. Museums however have taken a while to invest in digital storytelling. Their stories are complex and they often need multiple sources (maps, 3D, timelines, images, sound etc) to be fully exploited. For these reasons, they required the maturity of digitalization techniques, improvement in 3D restitution, data managing and research, as well as in internet itself, to fully express their commitment in digital narrative.
Currently, the increased attention of museums in digital storytelling is made tangible by the numerous research projects and publications that have been specifically approaching the matter. Surfing inside these sources of references we have verified that from the operational point of view digital storytelling in museums tends to be carried out in workshops following the process previously consolidated outside museums, that we propose below in museum version.

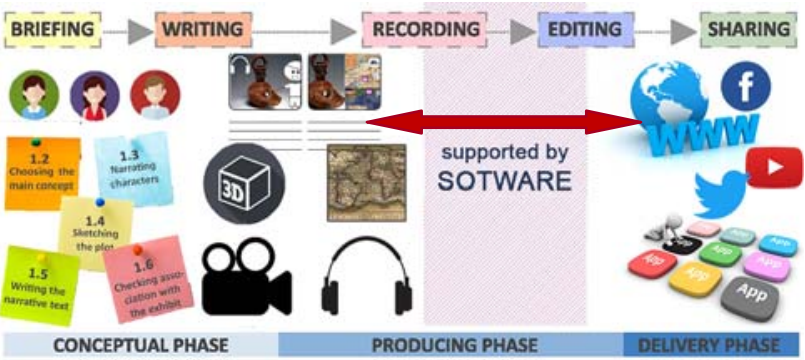

Figure 3. The five steps of digital storytelling production according to BBC model with reference to museums

The preliminary analyses also suggest that the producing phase (strongly depended by software features) has a primary role in particular for multimedia storytelling, intendent on "combining text and images with audio, video, graphics, and whatever medium is most appropriate for a given content or a given purpose" (Paolini \& Di Blas, 2014). This is the type of storytelling that we think could provide more opportunities for developing rich and engaging narrative about $\mathrm{CH}$.

We don't want to deny the importance of the conceptual phase that deserves, on its own, a thorough analysis, but working on the innovation of a narrative model, usually, cannot be easily pursued by museums autonomously. Actual opportunities to work in this direction are usually few due to lack of multidisciplinary competencies, information technologies (IT) expertise, and limited funds availability that characterize most medium and small institutions. A good example in this sense is provided by CHESS (an EU project that aims to implement and evaluate, in term of visitors' experience, the adoption of digital interactive stories for cultural sites and their authoring by the interdisciplinary cultural content experts) that has been proposing a personalized interactive digital storytelling model. In this case, one of the most challenging aspects, with multiple implications from writing to editing phase, has lied in proposing stories tailored to different users profiles. To do this, visitors "personas" have been created using detailed descriptions of imaginary people (constructed users model) that are empirically grounded to represent specific human beings. The CHESS model allows the association of particular story elements to a specific persona using a system of "persona tags". At a later stage, tags are translated into user characteristics and matched with users profiles. The project, to better support the personalization process, provides the CHESS Authoring Tool (CAT), desktop software environment, that authors use to design and implement the story. In CAT, it is possible to: "visualize the structure of the story, including the branching points that link to the different options that correspond to the visitor's choices; attach the relevant visual and audio assets to each part of the story; and publish the resulting multimedia narrative on the designated mobile device."

Considering the limits mentioned above to develop innovative models of digital storytelling designed as a function of museums' requirement, a wide investigation on existing software and tools have been carried out in order to identify 
alternative options that may be employed or relatively easily adjusted to this purpose.

\subsection{Tools for digital storytelling: critical overview}

Within the investigation on the existing tools and models research has been carried out with a twofold aim. Firstly, to understand which kind of narratives can be currently designed, and identifying, in the meanwhile, outlooks of further development. Secondly, the investigation provides a tentative SoA that can be a base and support for Museums interested in embracing digital storytelling.

Increasing number of storytelling tools available on the market confirms that resolve of storytelling is not declining in internet era. In spite the fact that written text remains essential for the narration, the survey has shown that the informative dimension is not merely the only base structure on which the other contents can be added as supporting actors. The release of visual, spatial and temporal based storytelling tools can be probably explained as an adaptation and reply of the market to current trend of digital contents consumption. Spatial dimension, as proven by numbers, 5/8 tools assume maps in quality of fundamental content, is leading this evolution. The possibility to "read-and-write" online maps has given rise to the geospatial web. Maps have become common in everyday life, people are accustomed to use web services such as Google Maps $\subseteq$ that have popularized and democratized the power of maps by enabling people to add and share cartographic contents (Giaccardi \& Fogli, 2008). Maps are more and more commonly used as an analytical tool to explore the spatial dimension of narratives (Caquard, 2013). The appearance of terms such as 'Story maps' (by Robert MacFarlane), 'fictional cartography', 'narrative atlas' and 'geo-spatial storytelling' are evidence of the growing interest in the relationship between maps and narratives. Maps may take on the role of "showcases" of plot of relations. They may: host multiplicity of point of views, enlarge the angle of prospective or be used like hand lens, welcoming a deeper meaning understanding.

Different narratives might be supported within the geospatial space as proposed for the Virtual Museum of Tremezzo, project made by Politecnico di Milano (Gicarus Lab - Dept. ABC) within the framework of Landscape museum of Como Lake, for which a specific multimedia-system has been designed to support the understanding of the values of Tremezzina's landscape among different targets such as tourist and locals. In this case, Landscape themes (historical sites, architecture, road network, land use artefacts and so on) and their transformations over time have been identified and highlighted combining use of historical maps and modern ones in order to support recognition of landscape values.

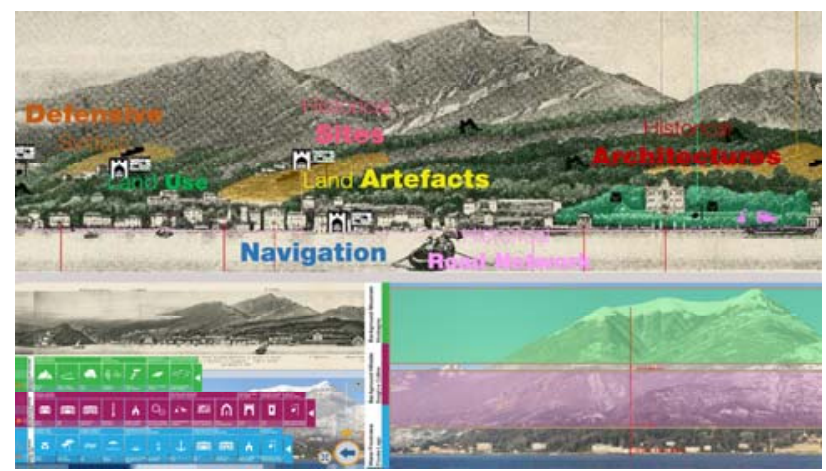

Figure 4. Geospatial space-time virtual navigation of themes and subthemes of Tremezzina environment, (C) Gicarus Lab
Connections, almost unknown nowadays, between Tremezzo and many cities in Europe, related to trade of local lemons' production by families of merchants, have been brought to light again using the geographic space as a plot to outline where gathered information and documents underling the impact of socio-economical pattern on territory development can be displayed. However, some technical constraints emerged during the design process, directly related to adoption of Google Earth $\odot$, further enhancements are advisable in term of contents delivery because the selected geospatial interface can host information only as additional layer (making difficult independent navigation by users) and graphic design improvements are not more possible with a consequent low grade of contents customization.

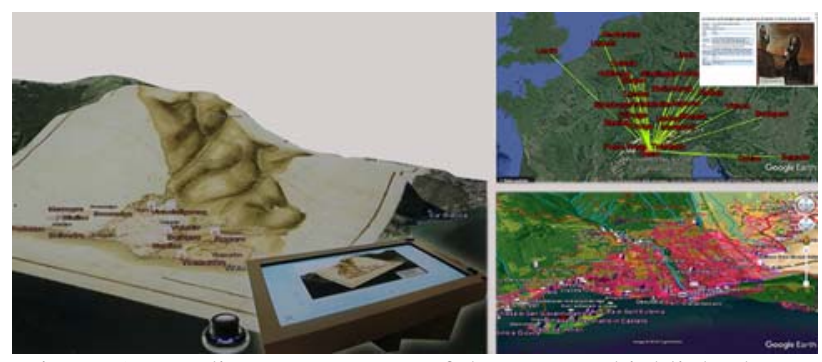

Figure 5. VM di Tremezzo: use of the maps to highlight theme \& subtheme of the territory, CGicarus Lab

Story Map ArcGis Esri@, currently one of the most featured tool for digital storytelling based on maps, moves exactly in the direction of geospatial narrative. It offers six semi structured models (sequential, series, comparative) suitable for likewise narrative styles that may be employed to overcome some of the constrains highlighted previously. In the footsteps of ArcGis, other mature map based tools such as Odyssey $@$ and Storymap JS $\odot$, investigated during the research process, offer diversified options for spatial narratives.

The survey has been carried out in form of a direct simulation of story development, using a linear progression of tools. To provide a useful comparison and assessment about completeness and flexibility of the tools we have selected the following main parameters: modality of log in access, contents and digital supported input sources, and compatible channels when sharing the story (particularly oriented in tracing interoperability with social media platforms).

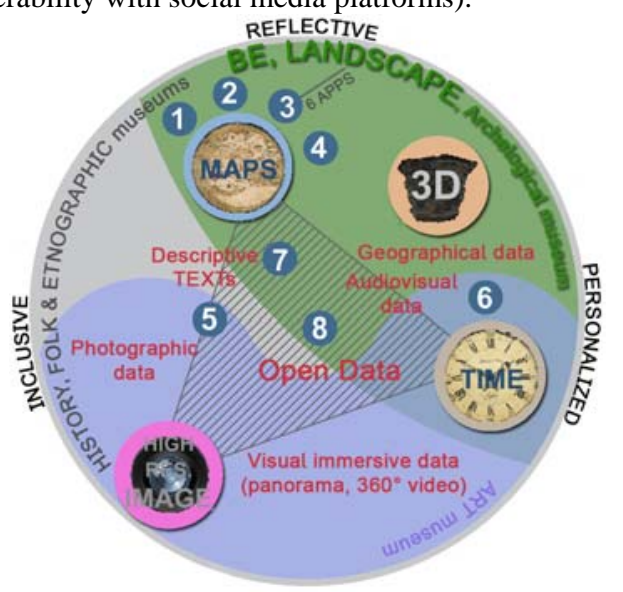

Figure 6. Surveyed tools (1. Google Tour Builder@), 2. Google My Map@, 3.Story Map ArcGis Esri@, 4. Odyssey® 5. Storymap JS Knightlab@, 6. Timeline JS Knightlab®, 7. Meograph@, 8. Atavist@), data that can be integrated (in red) and area of narrative interest for different kind of museums. 
It's worth recognizing that there is a palpable attempt of integration with most known social media (SM) platforms (at the top Facebook) in form of: media for log in, source for contents uploading and a channel for sharing as well. The tools intercept the broader trend regarding digital content consumption that is seen in social media, the prevalent platform for internet access and visiting time. Nevertheless, more effort should be put in interoperability story-social media platforms because the story, currently, can only be shared within SM in the form of a unappealing link. The instantaneous visualization of the contents is impeded, cutting drastically the potential attraction of user, as well as, diluting the power of inner mechanisms of contents' suggestion and re-share supported by SM. With the view of using SM as supplementary channel where bump into fleeing targets (in this sense teenagers might be a desirable and achievable target (Shaw \& Krug, 2013)) matter to which museums are thinking bashfully (as the early reports about use of social media for museums prove (4), this doesn't appear as secondary constrain.

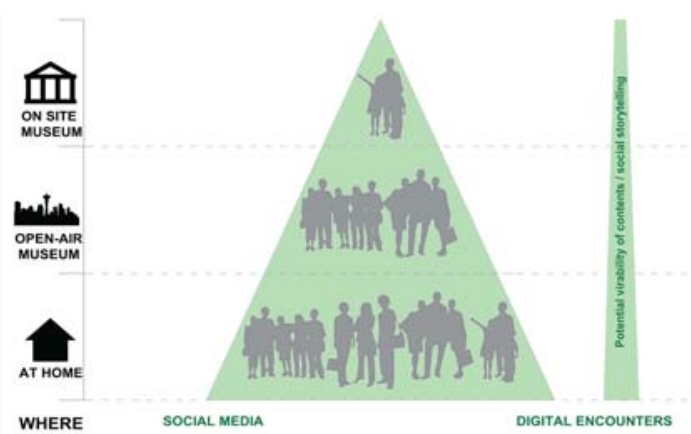

Figure 7. Scheme of potential social involvement using digital storytelling. Model from AT home (use of SM platform to spread the contents) to ON SITE museum (use of Beacon to deliver the story), (C) I-CULTMAP Project Proposal

Stories are designed according to a desktop-based approach. Reader modality is foreseen from desktop stations and mobile devices thanks to the automatic customization of story's layout by the tool. The opportunity to access stories from mobile devices allow professionals to think about their use as an additional source of information that visitor may choose according to their interest. Allowing visitors to see stories directly on their personal devices, within the physical space of museums using new technologies such as Beacon.

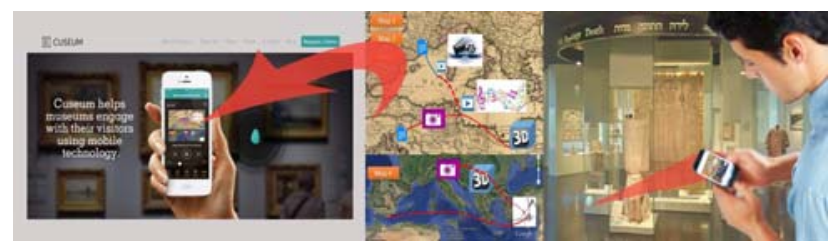

Figure 8. Exp. of Digital storytelling narrative in museums using Beacon, (C) I-CULTMAP Project Proposal

Nevertheless, working on interoperability of a story's format with a wider range of devices should be improved. We would like to stress, once more in this sense, looking at the matter from an additional point of view. Computers, smartphones and

\footnotetext{
${ }^{4}$ EMEE, 2014, TOOLKIT 5,

http://www.museums-exhibiting-europe.de/wp-

content/uploads/2016/01/EMEE_Toolkit_N5_DIG.pdf

\#SVEGLIAMUSEO, 2014, http://www.svegliamuseo.com/wp-

content/uploads/Ebook/Comunicare-la-cultura-online_Svegliamuseo.pdf
}

tablets have become part of material culture with great forcefulness, the mobile most of all, changing the paradigm of access to digital space. The new set of virtual reality (VR) and augmented reality (AR) devices, that are going to be broadly launched on the market, are seen as an additional disruptive chance within our grasp. Medium and low costs versions are already foreseen making customers' mouth water and social media platforms have loudly expressed their interest in contents compatible with these devices. These are all clues that from now on storytelling should be tailored also in this perspective if it would like to enhance immersivity of experience and offer stories that can benefit from access to 3D space and information in one environment

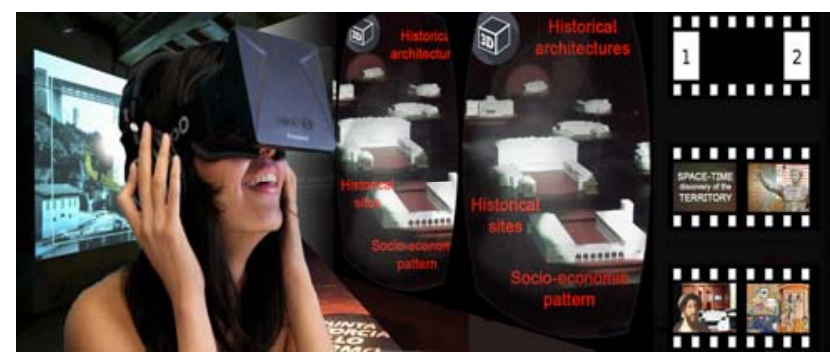

Figure 9. Hypothesis of Digital Storytelling for VR (3D+maps)

In the vein of what above, we would report a last consideration. The free tools tried are addressed to a wide range of stakeholders and not properly developed for museum storytelling. In this aspect, we ascribe a plausible reason for which 3D is not supported, either as structural space of narrative or content added within the narrative. Repository such as Europeana have been making great efforts in developing 3D contents as well projects such as CARARE, 3D-COFORM EU, 3D-ICONS etc. are investing in capturing techniques, post processing, publishing methodologies and online delivery. Therefore, we believe that investigating if and how the 3D can become an integral part of narrative is a paramount point of interest in order to enhance narrative capabilities.

\section{CONCLUSION}

Within the text the ongoing development of VMs has been briefly captured both as theoretical model and digital entity. Embracing the vision that a main feature/expectation of modern museums can be traced in their aptitude to be storytellers of the past, we proposed that VMs may have similar credibility by increasing in the area of effect. Storytelling supports meaning making, it makes accessible and comprehensible tangled relations. It may disclose the richness hidden behind cultural heritage becoming key for reading the past. According to this vision, we believe that new form of digital narrations may be an option to deal with the complexity of the system heritagememory-identity. Proposing compelling and multi-perspective stories about our origins within VMs, it is an option to which looking forward in future. Moreover, the time is ripe to think about VMs that go beyond the replica of single or multiple Institutions.

Having an overall vision on the tools for digital storytelling has allowed the understanding of what kind of narratives, at the state of the art, can be designed. It has been brought to light that written text is no more the unique scaffolding of narrative. Temporal, visual and geospatial dimension are offering additional peculiar models ready to be exploited. The first findings have suggested that these new forms offer valuable opportunities to re-use, disseminate and valorise digital data, 
especially open-data, in quality of contents. Open data is a fact and stories may only find benefit and enrichment if the challenge is tackled.

The direct investigation, has revealed that more than a simple look at social media is possible, but it is not fully actualized yet. Working on developing new format of output is a point that needs further investigation in the view of higher capability of adaptation to different platforms. Proposing stories customized for SM permits to intersect the potential of social platform from the point of view of dissemination of contents and involvement of fleeing target groups, youths more so than others. Similarly, it is important to work on compatibility with innovative AR and VR devices that can enhance the story in term of experience. At the same time, if from one side openness to storytelling in SM offers the mentioned opportunities, from another one, some threats are around the corner. Delivering digital contents within social media means to be obliged to face new intellectual properties issues. Contents, also when originally open access, become "property" of the SM platform. This matter is not easily solvable considering that researchers and museums are not so influential stakeholders to ask for changing the SM statutes. However, studying more in depth the topic is a point that should be in agenda.

Stepping back to narrative models, we saw that 3D contents are still pushed into a corner due to missing features of storytelling tools, although, 3D production has been living an increasing technical maturity. This fact raises our hopes that attempt a solution might be achievable soon in the interest of stories' effectiveness.

Tools of digital storytelling have shown that new models of narrative are already available. The tools can be used, at least the pre-structured narrative models, by users with low IT expertise. Under this condition, creating digital stories is possible for medium-small museums but, also for private users that may contribute or write directly their own cultural stories. Nevertheless, under this light, contents validation might become a thorny aspect that cannot be totally avoided in the future.

\section{ACKNOWLEDGEMENTS}

We thank Leoni Marco (Director of Landscape Museum of Como Lake) for the concession of museum's data and his support in developing the $\mathrm{PhD}$ research of which this paper presents a summary of preliminary findings.

This work has been supported by the GAMHer project: Geomatics Data Acquisition and Management for Landscape and Built Heritage in an European Perspective, PRIN, Progetti di Ricerca di Rilevante Interesse Nazionale - Bando 2015, Prot. 2015HJLS7E.

\section{REFERENCES}

Antinucci, F., 2007. The virtual museum. In: Archeologia e Calcolatori, Suppl. 1, pp. 79-86.

Athena Plus, 2015. Digital storytelling and cultural heritage: stakes and opportunitie, Report of AthenaPlus WP5 "Creative applications for the reuse of cultural resources", (http://www.athenaplus.eu/index.php?en/207/digital-storytelling-andcultural-heritage, accessed June 23, 2017).

Banfi, F., Barazzetti, L., Brumana, R., Oreni, D., Previtali, M., Roncoroni, F., Mazzetti, P., $2015 . \quad$ L'intermediazione geospaziale per la valorizzazione del paesaggio e lo sviluppo di sistemi museali multimediali. In: Atti Conferenza Nazionale ASITA, Lecco, Italy, pp. 811-820.

Bedford, L., 2001. Storytelling: The real work of museums. In: Curator: the museum journal, Vol. 44, Issue 1, pp. 27-34.

Bruner, J., 1991. The Narrative Construction of Reality. In: Critical inquiry, Vol. 18, No. 1, pp. 1-21.

Caquard, S., 2013. Mapping narrative cartography. In: Progress in Human Geography, Vol. 37, Issue 1, pp.135-144.

Castells, M., 2000. The construction of European Identity, Statement prepared for the European Presidency of the European Union, (https://www.chet.org.za/files/CASTELLS\%202004\%20European\%20I dentity.pdf, accessed June 23, 2017)

Chalcraft, J., Delanty G., 2015. Synthetic Report on Cultural Memory, Report of CulturalBase project for AXIS 1. Cultural memory,

(http://culturalbase.eu/documents/Synthetic\%20Report\%20on\%20Cultu ral\%20Memory.pdf, accessed June 23, 2017).

Diblasio, M., Diblasio, R., 1983. Constructing a Cultural Context through Museum Storytelling. In: Roundtable Reports, Vol. 8, No 3, pp. 7-9.

Giaccardi, E., Fogli, D., 2008. Affective geographies: toward a richer cartographic semantics for the geospatial web. In: AVI 8 Proceedings of the working conference on Advanced visual interfaces, Napoli, Italy, pp. 173-180.

Hooper-Greenhill, E., 2005. I musei e la formazione del sapere: le radici storiche, le pratiche del presente. Il Saggiatore, Milan.

Huhtamo, E., 2010. On the origins of the virtual museum. In: Museums in a Digital Age, Routledge, London, pp. 121-135.

Johnsson, E., 2006. Telling tales. A guide to developing effective storytelling programmes for museums. London Museums Hub, London.

Labov, W., Waletzky, J., 1967, Narrative Analysis: Oral Versions of Personal Experience. In: Essays on the Verbal and Visual Arts, June Helm, Seattle, pp. 12-44.

Macdonald, S., 2013, Memorylands: Heritage and Identity in Europe Today. Routledge, London.

Propp, V., 1968. Morphology of the folktale ( $2^{\text {nd }}$ edition). University of Texas Press, Austin.

Paolini, P., Di Blas, N., 2014. Storytelling for Cultural Heritage. In: Contin, A., Paolini, P., Salerno R., Innovative Technologies in Urban Mapping, Springer, Cham, pp. 33-45.

Poulot, D., 2015. Is the invention of memories necessary to identities?, Report of CulturalBase project for AXIS 1. Cultural memory, TF2. Memory and identities, (http://culturalbase.eu/documents/2.\%20POULOT.\%20Is\%20the\%20in vention\%20of\%20memories\%20necessary\%20to\%20identities.pdf, accessed June 23, 2017).

Roussou, M., Laia, P., Akrivi, K., Chrysanthi, A., Perry S. , Vayanou, M., 2015. The museum as digital storyteller: 
Collaborative participatory creation of interactive digital experiences. In: MW2015: Museums and the Web 2015, (http://mw2015.museumsandtheweb.com/paper/the-museum-as-digitalstoryteller-collaborative-participatory-creation-of-interactive-digitalexperiences/, accessed June 23, 2017).

Schweibenz, W., 1998. The "Virtual Museum": New Perspectives for Museums to Present Objects and Information Using the Internet as a Knowledge Base and Communication System. In: Proceedings des $6^{\circ}$ Internationalen Symposiums für Informationswissenschaft ISI, Prag, Czech Republic, pp. 185200.

Shaw, A., Krug D., 2013. Heritage Meets Social Media: Designing a Virtual Museum Space for Young People. In: Journal of Museum Education, Vol. 38, Issue 2, pp. 239-252.

Silvaggi, A., Braga P., 2013. Description of a digital Storytelling workshop in a museum context. In: Digital Storytelling an inclusive scientific museum: a European Project, Vetrani Editore, Nepi, pp. 49-55.

V-MUST, 2015. D. 2.3c State of the art on Virtual Museums in Europe and outside Europe, Report of V-MUST project, (http://www.v-

must.net/sites/default/files/D2.3d_StateArt_VirtualMuseums_2015.pdf, accessed June 23, 2017).

Wyman, B., Smith, S., Meyers, D., Godfrey, M., 2011. Digital Storytelling in Museums: Observations and Best Practices. In: Curator: The Museum Journal, Vol. 54, Issue 4, pp. 461-468.

Wong, A., 2015. The whole story, and then some: 'digital storytelling' in evolving museum practice. In: MW2015: Museums and the Web 2015, (http://mw2015.museumsandtheweb.com/paper/the-whole-story-andthen-some-digital-storytelling-in-evolving-museum-practice/, accessed June 23, 2017). 